\title{
Refuting tobacco-industry funded research: empirical data shows a decline in smoking prevalence following the introduction of plain packaging in Australia
}

\author{
Pascal A Diethelm ${ }^{1}$, Timothy M Forley²
}

\begin{abstract}
INTRODUCTION Legislation to introduce plain packaging of tobacco products, advocated as an important tobacco control policy in the Framework Convention on Tobacco Control, has been vigorously attacked by the tobacco industry on the grounds that it results in no measurable impact on smoking rates. This claim is based on two industry-funded working papers that examined trends in smoking prevalence in Australia.

OBJECTIVE To assess the effect of plain packaging on smoking prevalence in Australia, taking into account key tobacco control measures introduced over the period 2001-2013, which could potentially act as confounders, with the aim of investigating the findings of the industry-funded papers.

METHODS Monthly smoking prevalence and sample sizes from repeat cross-sectional surveys were reconstructed from the working paper by reverse engineering of the industry presented data and analysed as a time series using logistic regression. Indicator variables reflecting comprehensive smokefree policy, graphic health warnings, $25 \%$ taxation increase, and introduction of plain packaging were constructed from official information.

RESULTS Smoking prevalence in Australia declined from 25\% to $18 \%$ over the 13 year period examined - an overall $28 \%$ relative reduction or an average annual reduction of $2.8 \%$ (95\% confidence interval $2.6 \%-2.9 \%$ ). A significantly improved fit was obtained by the full model which included terms for tax increase $(4.8 \%, 2.7 \%-6.8 \%$ reduction), comprehensive smoke-free policy $(4.5 \%, 1.7 \%-7.2 \%$ reduction) and plain packaging $(3.7 \%, 1.1 \%-6.2 \%$ reduction) in addition to an adjusted average annual reduction of $1.7 \%(1.3 \%-2.2 \%)$.

conclusions A significant decline in smoking prevalence in Australia followed the introduction of plain packaging, after adjusting for the impact of other tobacco control measures. This conclusion is in marked contrast to that of the industry-funded analysis.
\end{abstract}

Tob. Prev. Cessation 2015;1 (November):6 http://dx.doi.org/10.18332/tpc/60650

\section{INTRODUCTION}

Guidelines on Article 13 of the WHO Framework-convention for Tobacco Control explain how Parties can fulfil their treaty obligations with respect to enacting and enforcing a comprehensive ban on tobacco advertising, promotion and sponsorship. Among the proposed measures, Parties are invited "to restrict or prohibit the use of logos, colours, brand images or promotional information on packaging other than brand names and product names displayed in a standard colour and font style." Australia was the first country to introduce this proposal by adopting the Tobacco Plain Packaging Act in November 2011 with progressive implementation between 1st October and 1st December 2012,3. The objectives of the plain (or standardized) packaging measure are to: "(a) reduce the appeal of tobacco products to consumers; and (b) increase the effectiveness of health warnings on the retail packaging of tobacco products; and (c) reduce the ability of the retail packaging of tobacco products to mislead consumers about the harmful effects of smoking or using tobacco products." At the time of writing, some countries (United Kingdom, Ireland) have decided to implement plain packaging and other countries (Finland, France, New Zealand, Norway, Sweden) are engaged in the process towards its adoption.

The multinational tobacco companies are intensively opposing the measure on several fronts, notably using international trade law and bilateral investment treaties to challenge Australia and threatening the other countries with large lawsuits and the spectre of billion-dollar financial 
compensations ${ }^{4}$. One key legal argument used by these companies invokes the principle of proportionality, which requires that any limitation on the exercise of rights and freedom may be made only if it is suitable to achieve its aim. In spite of mounting evidence to the contrary ${ }^{5}$, they claim this condition is not met in the case of plain packaging, contending that evidence of effectiveness of the measure is lacking.

They even go further, resorting to the classical ad ignorantiam argument ${ }^{6}$, shifting from absence-of-evidence to evidence-of-absence. In their response to the UK Department of Health's consultation on plain packaging, British American Tobacco (BAT) states that "the evidence to date from Australia shows that more than 18 months after its introduction, Plain Packaging has not had any effect on smoking behaviours beneficial to public health," referring to the Roy Morgan population survey data as evidence ${ }^{7}$. Similarly, JTI declared in its submission to the consultation that after 18 months, "the evidence actually emerging from Australia reinforces the fact that plain packaging does not work", citing two studies by A. Kaul and M. Wolf published on the website of the University of Zurich, which "have found that plain packaging has had no effect on smoking prevalence, either among minors or adults" and a report by a UK consultancy company, all three funded by Philip Morris ${ }^{8-10}$. A closer inspection reveals that the Roy Morgan population data cited by BAT designates the same two studies. In its response to the consultation, Philip Morris also refers to these studies, saying that "the experts found no evidence that 'standardised packaging' had had an effect on smoking prevalence among Australians," adding that they "confirmed that if there had been an effect in reality ... it would have been reflected in the data. ${ }^{11}$ "

These two studies are presented by one of their authors as the only papers on plain packaging "based on real-world data." 12 The authors also claimed that their methodology is the most apt at finding an effect associated with plain packaging: "Altogether, we have applied quite liberal inference techniques, that is, our analysis, if anything, is slightly biased in favor of finding a statistically significant (negative) effect [...]. Nevertheless, no such evidence has been discovered. More conservative statistical inference methods would only reinforce this conclusion." The two papers, which use nearly identical approaches, have been criticized for their methodological flaws ${ }^{13-16}$. Most critiques related to the first study (on minors), except Laverty et al. ${ }^{16}$ who looked at the second study (on adults). None was based on a re-analysis of the data used by the authors. In this article, we complement these critiques by re-analysing the data set used in the paper on smoking prevalence in adults, ${ }^{9}$ using a more appropriate method of analysis. The two authors further assume that in Australia, like in "all the OECD countries," there is a continuous downward trend in smoking prevalence which is best modelled by a declining straight line. They explain that "we see essentially the same line in all countries" regardless of whether they have "heavy anti-smoking measures" with a "minus 0.4 percentage point effect per year." ${ }^{17}$ Accordingly, this decline in prevalence observed over the past 15 years across OECD countries is the result of a "pre-existing" continuous and uniform trend. Two studies published in peer-reviewed journals ${ }^{18,19}$ contradict this assumption and strongly suggest that the evolution of smoking prevalence over periods which largely overlap the period considered by Kaul and Wolf was associated with the introduction of tobacco control measures.

Our objective hence was to assess the effect of plain packaging on smoking prevalence among adults in Australia based on the same data as Kaul and Wolf using a more appropriate statistical method and accounting for the potential effect of other key tobacco control measures.

\section{METHODS}

\section{Study Design and Sampling Procedure}

In their second working paper, Kaul and Wolf use Roy Morgan Research's Single Source (Australia) survey data ${ }^{20}$ over the time period January 2001 to December 2013, with a total sample size of about 700,000 observations ${ }^{9}$. The data were aggregated by month, with an average of 4,500 observations per month, to produce observed monthly prevalence estimates "as the average of $0-1$ variable smoker in the RMSS data that indicates whether an individual in the sample smokes." Roy Morgan Research's data are known for the consistency of their random sampling methods ${ }^{18}$ and have been used in previous research to obtain reliable estimates of smoking prevalence in Australia $^{18,19}$.

However, as the data used by Kaul and Wolf are not publicly available, we reconstructed them from Figures 1 and 2 in their paper on adults 9 . Since these figures are in vector graphics and can be greatly enlarged without loss of precision, we developed a method to reconstruct the original data points (see description of method, Python program and reconstructed data points in on-line material). For each of 156 months from January 2001 to December 2013 we estimated the percentage of smokers and size of the sample from the published figures and reconstructed the number of smokers and non-smokers in each sample. We were able to replicate results of the authors' weighted least square regression', corresponding to the straight line shown in their figure. To adjust for other tobacco control measures which may have confounded the 
estimated impact of plain packaging, we developed indicator variables for the introduction of comprehensive smoke-free policies, the introduction of graphic health warnings, and the large tax increase on tobacco products of April 2010. We did not include measures for which Wakefield and co-authors ${ }^{18,}$ ${ }^{19}$ found no significant effect on smoking prevalence, such as increased availability of smoking cessation medications, pointof-sale bans and partial smoking bans. Finally, we did not include in our analysis exposure to tobacco control mass media campaigns funded by the Australian government, as we do not have access to information on the dates of introduction nor the population coverage. We note however that these were found to make a negligible contribution to the reduction of smoking prevalence compared to the contributions of comprehensive smoke-free policies and tax increase ${ }^{19}$.

\section{Comprehensive smoke free policies}

Wakefield et al. ${ }^{18,19}$ treat smoke-free policies as a single intervention and build an indicator variable based on their level of implementation, attributing a score of 0 for no ban, 0.5 for partial bans and 1 for complete smoking bans. In their first paper, which looks at the period from June 1995 to December 2006, during which partial smoking bans were put in place, they observed "no effect of the implementation of smoke-free restaurant laws on smoking prevalence." On the other hand, Wakefield et al., ${ }^{19}$ looking at the period January 2001 to June 2011, during which comprehensive smoke-free policies were fully implemented, found that stronger smoke-free laws were associated with reduced smoking prevalence. We have therefore chosen to retain only comprehensive smoke-free policies with an indicator in the range 0 to 1 reflecting the proportion of the Australian population covered by such policies as they were progressively introduced in different Australian States and Territories (Table 1).

\section{Graphic health warnings}

Graphic health warnings on cigarette packs were gradually introduced in Australia starting in March 2006. By July 2006, more than half of the packs sold were compliant with the regulation ${ }^{19}$. Wakefield and colleagues found there was no significant difference in impact when the date of policy implementation was taken as March or July $2006^{19}$. As they did, we have opted for March 2006 as the date of implementation and have defined a graphic health warning (ghw) indicator variable with value 0 before March $2006(\mathrm{t}<63)$ and 1 from March 2006 onwards $(\mathrm{t} \geq 63$ ).

\section{Tobaccotax increases}

Significant increases in tobacco taxes are recognized as a highly effective tobacco control strategy ${ }^{23}$. During the period 20012013, two tax increases took place in Australia. On 29 April 2010 , a tax increase of $25 \%$ came into force, which was followed by another increase of 12.5\% in December 2013 . As this second increase came on the last month of our study period, we did not consider it and we built a tax indicator variable, with values 0 before May 2010 $(t<113)$ and 1 from May 2010 onwards ( $t \geq 1$ 13).

\section{Plain packaging}

According to a study on the introduction of plain packaging in Australia "the new standardised packs were available and likely already exerting an impact in the Australian market from October 2012 onwards, well before the 1 December mandated introduction date." 3 The same source indicates that in November 2012 more than half of the packs of cigarettes sold were in plain packaging. Furthermore, Quitline statistics indicate that the number of calls to the Quitline rapidly increased after 1 October 2012 to peak in November ${ }^{24}$. We have therefore chosen November as the month of onset of the plain packaging period and have defined the pp indicator variable with value 0 before November $2012(\mathrm{t}<143)$ and 1 from November 2012 onwards ( $\mathrm{t} \geq 143)$.

\section{Statistical analysis}

For the statistical analysis, a logistic regression model was used, as it is more appropriate for analysing proportions and percentages than the weighted linear regression model used by Kaul and Wolf. Together with the time variable (ranging from 1 to 156), we have included in the analysis the four indicator variables described above: Comprehensive smoke-free policy (smoke. free); graphic health warnings (ghw); $25 \%$ tax increase (tax); plain packaging (pp).

We ran stepwise (forward selection, backward elimination, both) logistic regression using the Akaike information criterion (AIC) to determine the final model. All analyses were performed with the $\mathrm{R}$ statistical programming language. We have also fitted a Loess non-parametric trend, in the same way as Kaul and Wolf did in their working paper, using R's loess function with the same default parameters ${ }^{9}$.

\section{RESULTS \& DISCUSSION}

The model which provides the best fit to the data comprises the time variable and three indicator variables, smoke-free policies, the $25 \%$ tax increase and plain packaging as explanatory variables. Stepwise regression resulted in the same final model (Table 2). In the full model, the contribution of graphic health warnings was negligible ( $\mathrm{p}$-value 0.925 ) and the term was not 
retained. The improvement in fit of the selected model over the simple model with time only is highly significant (chi-square goodness of fit statistic 34.8 on 3 d.f., $p<0.001$ ). Figure 1 shows the fit of the final logistic regression line to the data and compares the estimated trend line based on time only (average decrease of $2.78 \%, 95 \%$ CI $2.63 \%-2.93 \%$, per year) as well as the Loess nonparametric trend.

Our analysis shows that, when key tobacco control measures such as comprehensive smoke-free policies and increase of taxation on tobacco product are taken into account, the dataset used by Kaul and Wolf reveals a statistically significant reduction of smoking prevalence (of $3.7 \%$, p-value 0.006 ) following the introduction of plain packaging in Australia. While slightly smaller, this reduction is similar in magnitude to that of the two other tobacco control measures, known for their effectiveness, ${ }^{19}$ comprehensive smoke-free policies, associated with a $4.7 \%$ reduction of smoking prevalence and the $25 \%$ increase of tobacco taxation of 29 April 2010, associated with a further $4.8 \%$ reduction. Our results are consistent with the observation made by Commonwealth Treasury, which noted that tobacco clearances in Australia (including excise and customs duty) fell by $3.4 \%$ in 2013 relative to 2012 . Tobacco clearances are considered a reliable indicator of tobacco consumption in Australia ${ }^{25}$.

Although the statistical model we obtained is not very elaborate, controlling for only two key tobacco control measures, besides plain packaging, it provides a much better fit to the data than the crude linear model used by Kaul and Wolf, as shown by the improvement in the goodness of fit statistic indicated above. This is also visually verified by looking at the nonparametric Loess trend in Figure 1. Kaul and Wolf observed the discrepancy between the Loess trend and the time trend in the first three years. Rather than questioning the validity of their linear model, they simply cut off the first 42 months of observation, retaining only months $43-156$ for their analysis.

Our results show that this decision was not justified. Notwithstanding the jumps induced by indicator variables, the line corresponding to the fitted model time+smoke.free + tax + pp is quite consistent with the nonparametric Loess trend: the fitted model and the Loess curve almost coincide at the start and end of the period of analysis and are above or below the time trend almost simultaneously, crossing it nearly on the same months.

Table 1. Entry into force of comprehensive smoke free policies in Australian States and Territories. Column "Coverage (\%)" shows the percentage of the Australian population covered by comprehensive smoke free policies at the different dates' ${ }^{21}$. Estimated population (first quarter 2006) from Australian Bureau of Statistics ${ }^{22}$

\begin{tabular}{|c|c|c|c|c|c|c|}
\hline State territory & Entry into force & Month inder & Population & $\begin{array}{l}\text { Percent of } \\
\text { total pop. }(\%)\end{array}$ & Coverage $(\%)$ & $\begin{array}{l}\text { Number } \\
\text { of imonths }\end{array}$ \\
\hline (none) & Jan 2001 & 1 & & & 0 & 60 \\
\hline Tasmania & Jan 2006 & 61 & 489.140 & 2.40 & 2.40 & 6 \\
\hline Queensland & Jul 2006 & 67 & 3.987 .653 & 19.55 & 21.95 & 1 \\
\hline Western Australia & Aug 2006 & 68 & 2.042 .450 & 10.01 & 31.96 & 4 \\
\hline $\begin{array}{l}\text { Australian Capital } \\
\text { Territory }\end{array}$ & Dec 2006 & 72 & 334.229 & 1.64 & 33.60 & 7 \\
\hline New South Wales & Jul 2007 & 79 & 6.735 .528 & 33.02 & 66.63 & 0 \\
\hline Victoria & Jul 2007 & 79 & 5.048 .207 & 24.75 & 91.38 & 4 \\
\hline South Australia & Nov 2007 & 83 & 1.550 .135 & 7.60 & 98.98 & 32 \\
\hline Northern Territory & Jul 2010 & 115 & 208.347 & 1.02 & 100.00 & 42 \\
\hline Total & & & 20.395 .759 & & & 156 \\
\hline
\end{tabular}

Table 2. Results of logist ic regression analysis using the best fitting model time ${ }^{+}$smoke.free + tax + pp.

\begin{tabular}{|c|c|c|c|}
\hline $\begin{array}{l}\text { Explanatory } \\
\text { variable }\end{array}$ & $\begin{array}{l}\text { Parameter estimate } 95^{\circ} \text { confidence interval) } \\
\text { from logistic regression model }\end{array}$ & $\begin{array}{l}\text { Reduction in smoking } \\
\text { prevalence }(\%)\end{array}$ & p-value \\
\hline Time (year) & $-0.0173(-0.0218,-0.0127)$ & $1.71(1.27-2.16)$ & 0.0000 \\
\hline $25 \%$ tax increase & $-0.0488(-0.0703--0.0274)$ & $4.77(2.70-6.79)$ & 0.0000 \\
\hline Smoke-free policy & $-0.0462(-0.0750--0.0174)$ & $4.51(1.73-7.22)$ & 0.0017 \\
\hline Plain packaging & $-0.0372(-0.0638--0.0106)$ & $3.66(1.06-6.19)$ & 0.0061 \\
\hline
\end{tabular}


Kaul and Wolf explain that the Loess trend "provides a good local fit and avoids the problem of misspecification." "The adequacy between the Loess trend and our fitted model would tend to indicate that the latter is not grossly mis-specified.

While it is not possible to conclude that the decrease in smoking prevalence was caused by plain packaging, it remains that the new tobacco packaging policy constitutes, at least partly, one of the most plausible explanations for the observed decrease. Another factor which may have also induced a decrease in smoking prevalence is the enlarged and enhanced health warnings, which appeared on cigarette packs conjointly with the requirement for standardized packaging. It is however difficult to completely separate these two measures from each other as the larger health warnings are an integral part of the new pack design.

If further data confirm the observed decline in smoking prevalence noted in the 14 months from November 2012, this would indicate that the measure is associated with a stronger effect than anticipated. The Australian government only envisaged that plain packaging would "in the long term, as part of a comprehensive package of tobacco control measures, contribute to efforts to reduce smoking rates" ${ }^{26}$ Experts who commented on the measure before its implementation predicted that it would take more than two years to achieve its full impact ${ }^{27}$.

Coming from a household survey, the Roy Morgan' Single Source data are the result of self-reporting on smoking status, which could have been influenced by perceptual and attitudinal elements induced by the new standardized cigarette pack.
Following the introduction of plain packaging, respondents might have been more reluctant to declare themselves as smokers given the highly negative image of smoking depicted by the new packs with their enlarged pictorial health warnings. It should however be noted that self-reporting of smoking status is generally a reliable indicator ${ }^{28}$. Furthermore, as questions were embedded in an omnibus survey addressing not only smoking, the risk of underreporting of smoking status was reduced ${ }^{19}$.

A side product of our logistic regression analysis is the significant effect associated with both the comprehensive smokefree policies implemented during 2006-2007 in Australia and the April 2010 tax increase. This provides further confirmation that these two interventions are effective tobacco control measures, as already found by Wakefield and co-authors ${ }^{19}$. Tax increase appears to be the measure associated with the largest effect. According to the Guidelines for the implementation of Article 6 of the WHO Framework Convention for Tobacco Control, "Tax and price policies are widely recognized to be one of the most effective means of influencing the demand for and thus the consumption of tobacco products." On the other hand, the lack of effect associated with graphic health warnings is consistent with the results of Wakefield et al ${ }^{19}$. This does not mean that the measure is ineffective as graphic health warnings were introduced in the middle of the implementation of strict smoking bans and the dichotomous ghw indicator may be ill-suited to represent their characteristic wear-in/wear-out effect ${ }^{29}$.

To assess the robustness of our analysis, we have also run it with the assumption that the month of onset of the plain

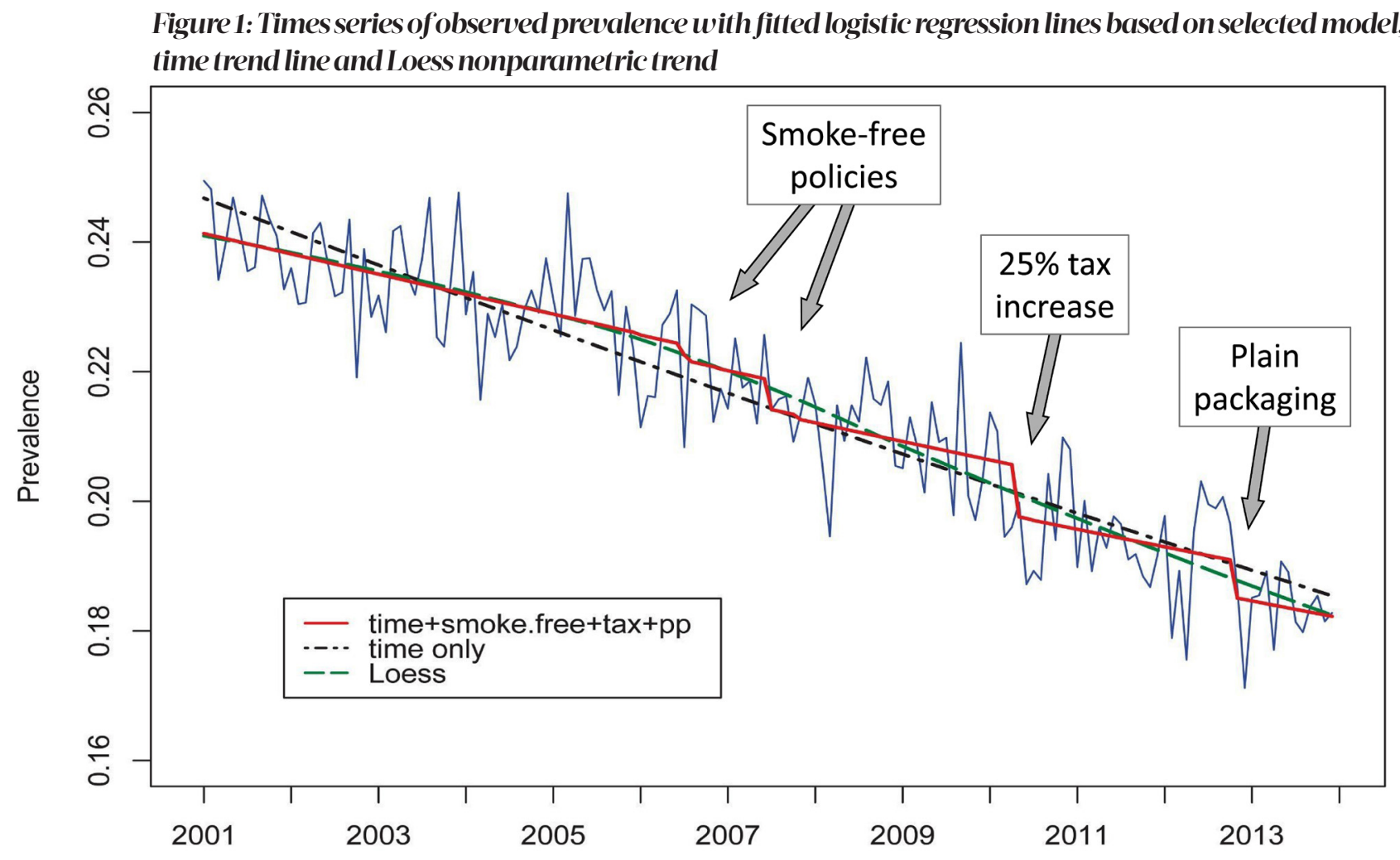


packaging period was December 2012, instead of November, with no notable differences in the results ( $\mathrm{p}$-value associated with the plain packaging effect was 0.007 instead of 0.006 ). The analysis presented above does not take into account the $12.5 \%$ tax increase which occurred on the last month of the period, in December 2013. To assess the impact of this decision, we have re-run the analysis excluding December 2013 (i.e. ending on month 155) and obtained almost identical results. Finally, the conclusions of the analysis presented above were qualitatively the same when repeated using weighted linear regression instead of logistic regression.

One limitation of the above analysis is that the data we used were obtained by reverse engineering from two figures in Kaul and Wolf's second paper, a process which may have introduced very small inaccuracies. However, our results are clear cut and the addition of random noise to the data that our method may have induced will have biased any true effects towards the null, leading to an underestimate of the impact. It should also be noted that the way the data were extracted from the Roy Morgan database and aggregated over month is important; however little information on how this was done is provided by Kaul and Wolf.

While our analysis uses a more realistic statistical model than the simple linear mode used by Kaul and Wolf in their working papers, additional analyses could be envisaged, using for instance the approach of Wakefield et al.., ${ }^{19}$ considering further explanatory variables and looking at State-specific smoking prevalence linked to the timing of introduction of the comprehensive smoke-free policies in each state.

Furthermore, the period of analysis we considered in this paper ends on December 2013 and does not include more recent observations. This was for two reasons. First, we wanted to reanalyse the data used by Kaul and Wolf, and therefore were restricted to the same period. Second, our attempts to obtain recent data directly from Roy Morgan were not successful due to budgetary considerations. Further statistical analysis should include recent data, covering in particular the whole of 2014 , to see whether and to what extent our results remain valid with new data and controlling in particular for the $12.5 \%$ tax increase of December 2013.

\section{CONCLUSIONS}

Our results do not support Philip Morris's assertions that there was no decrease in smoking prevalence after the introduction of plain packaging in Australia. The conclusion reached by Kaul and Wolf in their two papers was based on a subtle circular reasoning. They posited that the decrease of smoking prevalence observed in OECD countries, including Australia, follows a "preexisting" linear trend which is independent of tobacco control policies. Starting from the hypothesis that all tobacco control measures are ineffective, they arrived at the conclusion that there was no evidence of the effectiveness of one of them, plain packaging.

Using the same data set as Kaul and Wolf, we have shown in this paper that with the more realistic assumption that tobacco control measures can be potentially effective - as was shown by Wakefield et al. ${ }^{18,19}$ - we arrive at the conclusion that three key tobacco control measures that were introduced during the 13year period under study, namely comprehensive smoke-free policies, the large tax increase of April 2010 and plain packaging, were all associated with a clear and statistically significant reduction in smoking prevalence. This suggests consequently that all these measures were effective. In particular, the reduction in smoking prevalence that followed the introduction of plain packaging appears to have been even greater than expected.

\section{REFERENCES}

1. Framework Convention on Tobacco Control. Guidelines for Implementation of Article 11 (Packaging and Labelling of Tobacco Products). 2008. Available from: http://www.who.int/entity/fctc/ guidelines/article_11.pdf (accessed 11 Oct 2015)

2. Australian Government. Tobacco Plain Packaging Act 2011, An Act to discourage the use of tobacco products, and for related purposes, No. 148, 2011. Available from: http://www.comlaw.gov.au/Details/ C2013C00190 (accessed 11 Oct 2015)

3. Scollo M, Lindorff K, Coomber K, et al. Standardised packaging and new enlarged graphic health warnings for tobacco products in Australia - legislative requirements and implementation of the Tobacco Plain Packaging Act 2011 and the Competition and Consumer (Tobacco) Information Standard, 2011. Tob. Control 2015;24:ii9-ii16.

doi:10.1136/tobaccocontrol-2014-052073

4. Kennedy MS. Australia's Tobacco Plain Packaging Act: Convergence of Public Health and Global Trade. North Carolina Journal of International Law and Commercial Regulation. Volume 39 - Issue 2, Winter 2014, 591-629

5. See for instance the papers published in Tobacco Control, April 2015, Volume 24, Suppl. 2: Implementation and evaluation of the Australian tobacco plain packaging policy. Available from: http:// tobaccocontrol.bmj.com/content/24/Suppl_2.toc (accessed 11 Oct 2015)

6. Walton D. Appeal to ignorance, or Argumentum ad Ignorantiam. \ Argumentation. 13:367-377, 1999. Available from: http://www. dougwalton.ca/papers\%20in\%20pdf/99ignorantiam.pdf (accessed 11 Oct 2015)

7. British American Tobacco UK Ltd. Consultation on the Introduction of Regulations for the Standardised Packaging of Tobacco Products; Response of British American Tobacco UK Limited. 7 August 2014. Available from: http://www.bat.com/plainpackaging (accessed 11 Oct 2015)

8. Kaul A and Wolf M. The (Possible) Effect of Plain Packaging on the Smoking Prevalence of Minors in Australia: A Trend Analysis. University of Zurich Department of Economics Working Paper Series. May 2014; Available from: http://www.econ.uzh.ch/static/ workingpapers.php?id=828 (accessed 11 Oct 2015) 
9. Kaul A and Wolf M. The (Possible) Effect of Plain Packaging on Smoking Prevalence in Australia: A Trend Analysis. University of Zurich Department of Economics Working Paper, June 2014. Series. Available from: http://www.econ.uzh.ch/static/workingpapers. php?id=844 (accessed 11 Oct 2015)

10. Japan Tobacco International. JTI's response to the UK Department of Health's consultation on the introduction of regulations for standardised packaging of tobacco products. 6 August 2014. Available from http://www.jti.com/download_file/1569/629/ (accessed 11 Oct 2015)

11. Philip Morris Limited. Response to the Consultation on "Standardised Packaging". 7 August 2014. Available from: http://www.pmi. com/eng/tobacco_regulation/submissions/Pages/uk_standardisedpackaging-submission0812-2285.aspx (accessed 11 Oct 2015)

12. An interview with Dr Ashok Kaul. 15 April 2014 Available from: http://velvetgloveironfist.blogspot.fr/2014/04/an-interview-withdr-ashok-kaul.html (accessed 11 Oct 2015)

13. Cancer Council Victoria M, Australia. Comments on Kaul \& Wolf "The (possible) effect of plain packaging on the smoking prevalence of minors in Australia: a trend analysis". Available from: http:// www.cancervic.org.au/downloads/tobacco_control/2013/Cancer_ Council_Victoria_comments_on_Kaul_Wolf.pdf (accessed 11 Oct 2015)

14. Laverty AA, Watt HC, Arnott D, et al. Standardised packaging and tobacco-industry-funded research. The Lancet 2014; 383(9926): 1384. doi: 10.1016/S0140-6736(14)60499-2

15. Diethelm, P and McKee M, Tobacco industry-funded research on standardised packaging: there are none so blind as those who will not see! Tob Control Published Online First: 7 July 2014 doi: 10.1136/tobaccocontrol-2014-051734

16. Laverty AA, Diethelm P, Hopkinson NS, et al. Use and abuse of statistics in tobacco industry-funded research on standardised packaging. Tob Control Published Online First: 5 March 2015 doi: 10.1136/tobaccocontrol-2014-052051

17. Meeting to discuss "The (Possible) Effect of Plain Packaging on the Smoking Prevalence of Minors in Australia: A Trend Analysis" working paper. Attendees: Prof. Dr. Ashok Kaul, Saarland University; Prof. Michael Wolf, PhD, Zurich University; Christopher Cox, Review Secretariat; James Collis, Review Secretariat; Lucy Edwards (Notetaker). 20 March 2014. Available from: http:// www.kcl.ac.uk/health/Packaging-review/packaging-review-docs/ meetingsandbriefings/Professors-Kaul--Wolf-(University-ofZurich)-20-March-2014.pdf (accessed 11 Oct 2015)

18. Wakefield MA, Durkin S, Spittal MJ, Siahpush M, Scollo M, Simpson JA, et al. Impact of tobacco control policies and mass media campaigns on monthly adult smoking prevalence. Am J Public Health. 2008;98:1443-50. doi: 10.2105/AJPH.2007.128991

19. Wakefield MA, Coomber K, Durkin SJ, Scollo M, et al. Time series analysis of the impact of tobacco control policies on smoking prevalence among Australian adults, 2001-2011. Bull World Health Organ 2014; 92:413-422 doi: 10.2471/BLT.13.118448

20. Roy Morgan Research. How we collect and process Single Source data in Australia. Melbourne (Australia). Roy Morgan Research. Available from: http://www.roymorgan.com/products/singlesource/single-source-fact-sheets (accessed 11 Oct 2015)

21. Wikipedia. List of smoking bans in Australia. Wikipedia. Available from: http://en.wikipedia.org/wiki/List_of_smoking_bans_in_
Australia (accessed 11 Oct 2015)

22. Estimated Resident Population, States and Territories. [Catalogue no. 3101.0] Australian Bureau of Statistics, Commonwealth of Australia; 2015.

23. IARC Handbooks of Cancer Prevention, Tobacco Control, Vol. 14: Effectiveness of Tax and Price Policies for Tobacco Control. 2011: Lyon, France

24. Young JM, Stacey I, Dobbins TA, Dunlop S, et al. Association between tobacco plain packaging and Quitline calls: a populationbased, interrupted time-series analysis. MJA 2014; 200: 29-32. doi: 10.5694/mja13.11070 Available from: https://www.mja.com. au/system/files/issues/you11070_fm.pdf (accessed 11 Oct 2015)

25. Australian Government, Department of Health. Tobacco key facts and figures. Available from: http://www.health.gov.au/internet/ main/publishing.nsf/Content/tobacco-kff (accessed 11 Oct 2015)

26. Australian Government, Department of Health. Introduction of Tobacco Plain Packaging in Australia. Available from: http://www. health.gov.au/internet/main/publishing.nsf/Content/tobacco-plain (accessed 11 Oct 2015)

27. Pechey R, Spiegelhalter D, Marteau TM. Impact of plain packaging of tobacco products on smoking in adults and children: an elicitation of international experts' estimates. BMC public health 2013;13:18 doi:10.1186/1471-2458-13-18

28. Wong SL, Shields M, Leatherdale S, Malaison E and Hammond D. Assessment of validity of self-reported smoking status Statistics Canada, Catalogue no. 82-003-XPE, Health Reports, Vol. 23, no. 1, March 2012. Available from: http://www.statcan.gc.ca/pub/82003-x/2012001/article/11625-eng.pdf (accessed 11 Oct 2015)

29. White V, Bariola E, Faulkner A, Coomber K, Wakefield M. Graphic health warnings on cigarette packs: how long before the effects on adolescents wear out? Nicotine Tob Res first published online September 19, 2014 doi:10.1093/ntr/ntu184 